\title{
Use of slag (with cement) for improving the performance of expansive soil of road pavement subgrade
}

\author{
Agus Ika Putra ${ }^{1 *}$ and Mohamed A. Shahin ${ }^{2}$ \\ ${ }^{1}$ Department of Civil Engineering, Universitas Riau, Pekanbaru, Indonesia \\ ${ }^{2}$ Department of Civil Engineering, Curtin University, Perth, WA, Australia
}

\begin{abstract}
The study presented in this paper evaluates the suitability of using slag (with cement) as a stabilizer, for improving the performance of expansive subgrade soil in road pavement. Several laboratory tests were conducted to determine the geotechnical engineering characteristics of the expansive soil and associated mechanical engineering performance. The tests conducted include the particle size distribution, standard Proctor compaction, Atterberg's limits, free swelling, permeability, California bearing ratio (CBR), unconfined compressive strength (UCS), and repeated load triaxial (RLT). In this study, the use of slag (with cement) as a stabilizer followed three proportion schemes, and the selection of a specific stabilizer proportion was determined based on UCS value that satisfies the required standard as a subgrade for road pavement. The results recommended a stabilizer proportion for the soil studied to be $13.5 \%$ slag + $1.5 \%$ cement at 28 days curing time. This mixture resulted in a remarkable increase in the UCS value of eight times higher than the UCS value of the non-stabilized soil. The CBR value of the mixture was four times higher than the minimum required value for design of road pavement. The study presented herein confirmed that the exploitation of the by-product material of slag can indeed be useful, both in terms of improving the performance of the subgrade soil for road pavement and sparing the environment a spread of significant potential pollutant.
\end{abstract}

\section{Introduction}

In general, road pavement layers consist of several layers of different materials that function systematically, as shown in Fig. 1. Each layer has a certain thickness to support loads derived from traffic loads which then transfer these loads to the subgrade. The subgrade may be either a native soil or an imported material. If the found native soil is deemed insufficient to have adequate carrying capacity as subgrade, it is usually treated (stabilized) appropriately. This is done to avoid the high costs that may arise to when bringing material from other places. To determine the type of stabilization to be carried out, a series of investigations in the laboratory is needed to determine the bearing capacity of the

\footnotetext{
*Corresponding author: agusip@eng.unri.ac.id
} 
stabilization results. Stabilized soil bearing capacity is usually associated with specific geotechnical properties of the soil mixture.

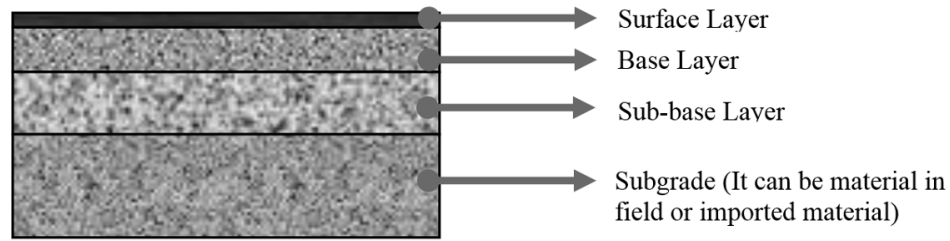

Fig. 1. Main components of road pavement layers.

One type of natural soil that is considered problematic if it is below the pavement layer is reactive soil or expansive soil. This soil is in the form of clay which predominantly contains montmorillonite minerals. This soil tends to experience swelling with increased moisture content and conversely shrinks if there is a decrease in moisture content. Fluctuations in moisture content in the soil usually occur due to environmental conditions that often change, especially the influence of seasons on the area. Changes in expansive soil volume due to shrinkage and swelling will lead to soil deformation in a specific direction. The direction of deformation that occurs depends on the existing boundary conditions. In the case of road pavement layer, this deformation will cause substantial distortion of the road surface. For example, the expansive soils commonly exist in most areas of Australia are known to cause enormous damage to buildings and roads [1,2].

Swelling and shrinkage of expansive soil are affected by the following factors: type and amount of clay minerals and cautions, water content, dry density, soil structure, and loading conditions. Based on a lot of literature, many methods, and tests have been carried out which aim to reduce volume changes in expansive soil due to the influence of changes in water content. The technique generally performed there is chemical stabilization, which is by mixing some certain compound materials which will then emerge a chemical reaction that aims to change the properties of expansive soil. The addition of lime, cement, fly-ash and other chemical compounds as additives in the soil stabilization process has been successfully adopted for years [3].

To minimize the cost of subgrade stabilization and reduce the adverse environmental impact, road planners tend to reuse industrial waste for soil subgrade stabilization. One of the irons making industrial wastes is the ground granulated blast furnace slag (GGBFS), which has been lately utilized as a stabilizer material for general ground improvement purposes. The role of slag in improving the performance of soil slag mixtures is almost the same as the role of cement in the soil-cement mixture. The chemical composition of the slag is very identical to the chemical composition in cement, which contributes to the cementitious, pozzolanic, and hydration reactions. The Australasian Slag Association reported that the slag production from the iron and steel industry in Australia is huge, amounting to 3 some million tonnes per year [4]. Management of such amount warrants a wider use of slag in civil engineering projects and infrastructure systems, to offer a costeffective and environmentally-friendly disposal method of this waste by-product.

Many researchers have investigated the utilization of GGBFS for soil stabilization. For example, the study carried out by Veith [5] showed that the addition of slag into expansive soil could reduce the swelling potential of the soil from more than $28 \%$ to only $4 \%$. The reduction of swelling potential is attributed to the formation of cementitious gels when the slag is activated with a small percentage of lime. With the establishment of this cementitious gels, soil particles will be bound to each other. This bond will withstand the pressure of expansive particles if the soil is exposed to water. Yadu and Tripathi [6] mixed one type of slag, GGBFS, with variations in proportions of $3 \%, 6 \%, 9 \%$, and $12 \%$ of the 
weight of soft soil. This soft soil is classified as clay with the silt of intermediate compressibility. The mixture of soft soil and slag were then tested in a laboratory to determine the effect of slag on the performance of the soft soil. It was found that there was a decreasing trend of both the liquid limit and plastic limit when the slag was added. For example, the plasticity index decreased from $17 \%$ without slag to $13 \%$ with $9 \%$ slag. Yadu and Tripathi [6] also reported a reduction in swelling pressure from $42 \mathrm{kPa}$ without slag to $34 \mathrm{kPa}$ with $9 \%$ slag. Even with the addition of $6 \%$ slag, there was an increase in the UCS value from $118 \mathrm{kPa}$ to $155 \mathrm{kPa}$, and the same trend was observed for the CBR test results. The CBR values were found to be equal to $20 \%$ for $6 \%$ slag of unsoaked samples, and $10 \%$ for $9 \%$ slag of soaked samples cured for four days. Based on all results, it can be concluded that adding a certain amount of slag to the soil can improve the overall soil performance.

In order to provide sufficient alkalinity to activate the GGBFS or slag and to modify the soil, GGBFS is commonly mixed with other additional stabilizing materials such as lime or cement into a soil. For example, Ouf [7] used a combination of GGBFS and lime as stabilizers to treat expansive clay from Egypt. He noted that when GGBFS is used solely (as a stabilizer) with soil, the pozzolanic reaction between the soil and GGBFS is relatively slow. This slow rate of pozzolanic reaction is advantageous, since it provides enough time for finalizing any stabilization engineering work in the field, for example, providing appropriate time for the process of subgrade mixing and compaction. Ouf [7] also found that adding $6 \%$ slag alone can increase the UCS value for 7 and 28 days curing periods. The increase in the UCS value was linked to increasing the slag plus hydrated lime. It was found that adding $6 \%$ slag with up to $30 \%$ hydrated lime (as soil dry weight replacement) showed a remarkable increase in the UCS value of the mixture. Higgins [8] indicated that a commonly used stabilizing blend in Australia comprises of $85 \%$ slag and $15 \%$ hydrated lime effectively combats the expansion associated with the presence of sulfate in soil and equally combats extension associated with sulfides such as pyrites. Another study was performed by Kavak et al. [9] on a low-plastic soil stabilized with lime and GGBFS using seawater for the hydration process (i.e., curing). The UCS and CBR tests were conducted on soil samples treated with 5\% lime and 3.3\% slag, and these mixtures were cured for 28 days. Kavak et al. [9] concluded that the optimum results were obtained when the lime to slag ratio was $1.5: 1$ by weight. Using this ratio, the UCS value of the treated soil was increased to more than eight times of the initial UCS value of the untreated soil (i.e., reference value), reaching $2500 \mathrm{kPa}$. The CBR values of soaked samples also increased to more than ten times the reference values. From this study, Kavak et al. [9] concluded that lime and slag could be used in combination as a useful additive to treat expansive soils, and mentioned that a certain amount of lime was needed to activate the slag.

A stabilizer made of a combination of slag and cement to treat expansive soils was investigated by Cokca et al. [10], who utilized slag accompanied with cement to decrease soil expansiveness. A mixture of slag and cement was added to treat expansive soil samples in proportions of $25 \%$ and $75 \%$ by weight, respectively. The results of the study indicated that treatment with slag and cement altered the grain size distribution of the expansive soils, the plasticity index decreased and specific gravity increased, and the swelling magnitude decreased as well as the time to reach $50 \%$ of the total swelling values. Lu et al. [11] mixed $10 \%$ and $15 \%$ cement with soil before adding slag in various proportions and noted that the UCS values of the cement-stabilized soil increased by adding slag at 5\%,10\%, 15\%, and $20 \%$ for curing times of 7,14 , and 28 days.

In this paper, an expansive soil from Perth in Western Australia was stabilized with slag accompanied with cement, mixed in certain proportions for road construction. The objectives of the study are: (i) to determine the optimum ratios of a stabilizer comprising slag and cement for improvement of the expansive soil such that the resulting soil can meet the allowable standard for subgrades in road pavements, (ii) to evaluate the performance of 
the selected stabilized soil in terms of strength, bearing capacity and resilient modulus, and (iii) to investigate the correlation between the resilient modulus of the selected maintained soil and applied stresses.

\section{Materials and methods}

\subsection{Materials}

The soil used in this research is an expansive natural soil obtained from Baldivis area in Perth, Western Australia. The procedures of soil sampling and preparation were conducted following the Australian Standard AS 1289 [12]. The expansive soil layer in Baldivis area was located beneath a surface layer of sandy soil. The sampling process was carried out by a mini excavator, and the soil in the excavator bucket was checked regularly to make sure that the expansive soil extracted was not contaminated with any other soil or organic materials. The stabilizers used were GGBFS and local suppliers in Western Australia provided ordinary Portland cement, both of them. The chemical and physical properties of the GGBS used are shown in Tables 1 and 2, respectively.

Table 1. Chemical properties of the GGBFS used.

\begin{tabular}{|c|c|}
\hline Component & Content (\%) \\
\hline Calcium Oxide $(\mathrm{CaO})$ & $30-50$ \\
\hline Silica, Amorphous $\left(\mathrm{SiO}_{2}\right)$ & $35-40$ \\
\hline Aluminium Oxide $\left(\mathrm{Al}_{2} \mathrm{O}_{3}\right)$ & $5-15$ \\
\hline Sulphur $(\mathrm{S})$ & $<5$ \\
\hline
\end{tabular}

Table 2. Physical properties of the GGBFS used.

\begin{tabular}{|c|c|}
\hline Property & Value \\
\hline Bulk unit weight (loose) & $(10.0-11.0) \mathrm{kN} / \mathrm{m}^{3}$ \\
\hline Bulk unit weight (vibrated) & $(12.0-13.0) \mathrm{kN} / \mathrm{m}^{3}$ \\
\hline Surface area & $(400-600) \mathrm{m}^{2} / \mathrm{kg}$ \\
\hline
\end{tabular}

\subsection{Treatment procedure}

Expansive soil used was treated in such a way as to fulfill specific criteria to be more easily processed in the mixing stage. The soil was conditioned in a dry condition and has passed a $2.36 \mathrm{~mm}$ sieve. When the mixing process commenced, the soil taken from the storage container which usually contained a small amount of water was re-examined for its initial water content. A standard microwave unit and a set of desiccators were used to determine the initial water content immediately.

The value of the initial water content was taken as a reference to determine how much water is added to cover the range of moisture content intended for the test (which also embraces the optimum value). Based on previous studies, the use of $15 \%$ (of the dry soil) combined slag and Portland cement was deemed adequate. This proportion of stabilizers 
was divided into three combinations of slag plus cement at different slag to cement ratios: $100 \%$ slag $-0 \%$ cement, $90 \%$ slag $-10 \%$ cement, and $85 \%$ slag $-15 \%$ cement.

Amount of soil that has fulfilled the mixing criteria was poured into an electrical mixing machine equipped with a stirrer and timer. The additive material that has been determined by weight were then poured evenly and slowly over the soil. The mixing apparatus was run for about 1-2 minutes until the mixture becomes homogeneous then a certain amount of water was added slowly while mixing. The amount of water added was based on the calculation of the percentage of water at the optimum moisture content determined from the compaction tests for each mixture composition. The stabilized soils were compacted using the standard Proctor compaction test procedure. The compacted stabilized soils were removed from the compaction mold using a mechanical hydraulic jack, the specimens were then wrapped with plastic bags and cured over three different periods of time (i.e. 7, 14, and 28 days), with at least four identical specimens for each period. The results presented herein are the average of the three adjacent values of the four samples.

\subsection{Laboratory tests}

The geotechnical tests on the untreated soil included the grain size distribution, Atterberg's limits, free swelling and compaction in accordance to Australian Standard AS 1289 [12].

Table 3. Stress combinations used in the RLT tests according to AASHTO T307-99.

\begin{tabular}{|c|c|c|c|c|c|}
\hline $\begin{array}{c}\text { Sequence } \\
\text { No }\end{array}$ & $\begin{array}{c}\text { Confining } \\
\text { pressure, } \mathbf{s} 3 \\
\mathbf{( k P a})\end{array}$ & $\begin{array}{c}\text { Maximum } \\
\text { axial stress, } \\
\text { Smax (kPa) }\end{array}$ & $\begin{array}{c}\text { Cyclic } \\
\text { stress, scyclic } \\
\mathbf{( k P a )}\end{array}$ & $\begin{array}{c}\text { Seating } \\
\text { stress, 10\% } \\
\text { smax (kPa) }\end{array}$ & $\begin{array}{c}\text { No of load } \\
\text { cycles }\end{array}$ \\
\hline 0 & 41.4 & 27.6 & 24.8 & 2.8 & $500-1000$ \\
\hline 1 & 41.4 & 13.8 & 12.4 & 1.4 & 100 \\
\hline 2 & 41.4 & 27.6 & 24.8 & 2.8 & 100 \\
\hline 3 & 41.4 & 41.4 & 37.3 & 4.1 & 100 \\
\hline 4 & 41.4 & 55.2 & 49.7 & 5.5 & 100 \\
\hline 5 & 41.4 & 68.9 & 62 & 6.9 & 100 \\
\hline 6 & 27.6 & 13.8 & 12.4 & 1.4 & 100 \\
\hline 7 & 27.6 & 27.6 & 24.8 & 2.8 & 100 \\
\hline 8 & 27.6 & 41.4 & 37.3 & 4.1 & 100 \\
\hline 9 & 27.6 & 55.2 & 49.7 & 5.5 & 100 \\
\hline 10 & 27.6 & 68.9 & 62 & 6.9 & 100 \\
\hline 11 & 13.8 & 13.8 & 12.4 & 1.4 & 100 \\
\hline 12 & 13.8 & 27.6 & 24.8 & 2.8 & 100 \\
\hline 13 & 13.8 & 41.4 & 37.3 & 4.1 & 100 \\
\hline 14 & 13.8 & 55.2 & 49.7 & 5.5 & 100 \\
\hline 15 & 13.8 & 68.9 & 62 & 6.9 & 100 \\
\hline
\end{tabular}


To determine the grain size distribution, the sieve analysis method was performed on the sand-size fraction of the soil (i.e., larger than $75 \mu \mathrm{m}$ ), whereas the sedimentation method using the hydrometer was conducted for the soil particles less than $75 \mu \mathrm{m}$. The liquid limit was determined using the Casagrande apparatus, and the plastic limit was obtained from the typical $3 \mathrm{~mm}$ threads. The free swelling was resolved using a graduated cylinder containing a dry soil specimen filled with distilled water. The soil specimen was left for 24 hours for absorption, and the final volume of soil was measured to calculate the soil free swell index. The compaction test was carried out to obtain the maximum dry density (MDD) and corresponding optimum moisture content (OMC) using Proctor tests.

The geotechnical testing conducted on the treated soils include the acidity and basicity measurements (this was made on both the natural and stabilized soils using a portable digital reading $\mathrm{pH}$ meter), permeability, unconfined compression strength (UCS), California Bearing Ratio (CBR), and repeated load triaxial (RLT). All experiments were conducted following the Australian Standard AS 1289 [12], except the RLT tests which were performed following the procedures of the American of State Highway and Transportation Officials AASHTO T307-99 [13]. The UCS tests were performed using a triaxial apparatus equipped with fully computerized facilities and necessary software to carry out all stages of the analysis automatically. The CBR tests were conducted after 28 days of curing and after soaking into the water for four days at a constant temperature before being tested. Loading the CBR samples was performed using a universal testing machine which can record both the load and displacement automatically. The RLT tests were also performed using a universal testing machine. Details of the various stress combinations applied during the 15 loading cycles are shown in Table 3 . In every loading cycle, constant seating stress equal to $10 \%$ of the maximum axial stress was also applied. The minimum deviatoric stress applied during each cycle was maintained at zero value.

\section{Results and discussion}

The results of the sieve analysis and hydrometer test on the original soil showed the grain size distribution consists of a sand fraction of $19 \%$, a silt fraction of $52 \%$, and a clay fraction of $29 \%$. From the measurements, the liquid limit (LL) and plastic limit (PL) were found to be 68 and 41, respectively, resulting in a plasticity index (PI) of 27. Based on the hydrometer test, on average, the percentage of particle size less than $425 \mu \mathrm{m}$ was $93 \%$. According to the Austroads Guide of Pavement Technology, the degree of expansiveness can be calculated as $(\mathrm{PI}) \times(\%<425 \mu \mathrm{m})=27 \times 93=2511$, which can be classified as moderate to high. Furthermore, based on the percentage of clay, the soil activity index (A) was calculated to be equal to 1.5 , which also classifies the soil as being active $(A>1.25)$.

Table 4. Values of OMC and corresponding maximum dry unit weight of soils.

\begin{tabular}{|c|c|c|c|}
\hline Soil mixture & $\begin{array}{c}\text { Sample } \\
\text { code }\end{array}$ & $\begin{array}{c}\text { Optimum Moisture } \\
\text { Content }(\%)\end{array}$ & $\begin{array}{c}\text { Maximum dry unit } \\
\text { weight }\left(\mathbf{k N} / \mathbf{m}^{\mathbf{3}}\right)\end{array}$ \\
\hline Soil alone (non-stabilized) & - & 29.5 & 13.5 \\
\hline Soil + 15\% slag & Mix-1 & 29.0 & 13.8 \\
\hline Soil + 13.5\% slag + 1.5\% cement & Mix-2 & 28.6 & 13.9 \\
\hline Soil + 12.75\% slag + 2.25\% cement & Mix-3 & 29.4 & 13.6 \\
\hline
\end{tabular}

For the free swell measurement, the soil specimen in distilled water experienced a free swell index of $91 \%$, which indicates that the degree of expansion of this soil is Medium. 
The optimum moisture content (OMC) of non-stabilized and stabilized soils and corresponding maximum dry density (MDD) obtained from the standard Proctor tests are presented in Table 4. As can be seen, a sample code (column 2) is used for the mixtures tested, and the results indicate that the values of OMC and MDD for all tested mixtures are not very dissimilar. Compared with the non-stabilized soil, higher MDD values are obtained for the stabilized samples; this is attributed to the replacement of soil by the slag and cement, which both have relatively higher specific gravity than the soil. On the other hand, lower OMC values of the mixtures compared to that of the non-stabilized soil is attributed to the decreased quantity of free soil, hence smaller surface area needs less water.

Fig. 2 shows the compaction curves for the mixtures tested concerning the dry unit weight versus water content for the standard compaction effort. It can be seen that Mix-3 (i.e., soil mixture with $13.5 \%$ slag $+1.5 \%$ cement) has a different trend compared to the compaction curves of the non-stabilized soil and other mixtures; it also has the highest maximum dry unit weight $\left(13.9 \mathrm{kN} / \mathrm{m}^{3}\right)$ and lowest optimum moisture content $(28.6 \%)$. The replacement of $0.75 \%$ slag to cement on this mixture appeared to have led to the need for additional water of $0.85 \%$ in the mix to achieve its maximum dry density. The optimum moisture content values were used in the preparation of the specimens for the RTL tests.

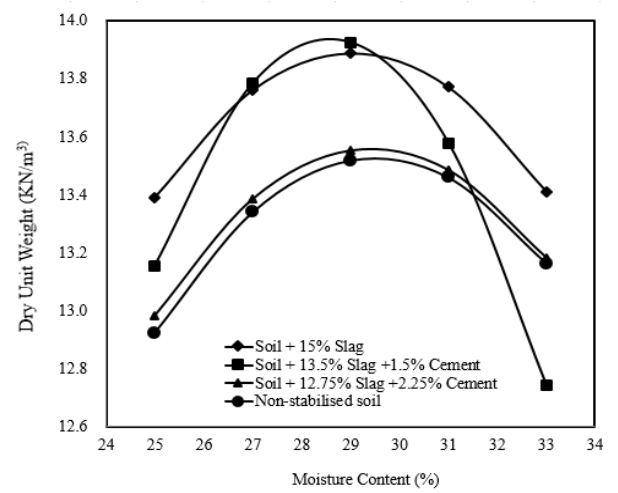

Fig. 2. Compaction curves of non-stabilized and stabilized soils.

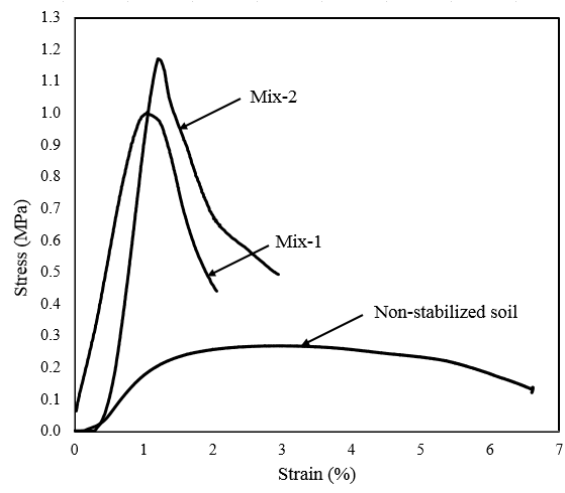

Fig. 3. Stress-strain curves of UCS tests for non-stabilized and stabilized soils at $7^{\text {th }}$ day.

The acidity and basicity measurements were performed on both non-stabilized and selected stabilized soil contained $13.5 \%$ slag $+1.5 \%$ cement. The results indicate that the $\mathrm{pH}$ values changed from $\mathrm{pH}$ of 6.1 for the non-stabilized soil to the basicity area with a $\mathrm{pH}$ of 11.6 for stabilized soil. The increase in $\mathrm{pH}$ value after the stabilization process is due to the effect of the pozzolanic reaction between the soil and stabilizing materials (GGBFS and cement), which produces a compound of alkaline nature. The higher $\mathrm{pH}$ level is expected since it can change the toxic metals into less hazardous material.

The permeability test was performed on the stabilized soil for three days. Over this period, no significant change of the water height in the standpipe was observed, and no water flow through the outlet permeameter cylinder was collected. To examine this, the permeameter baseplate was removed for inspection, and it was found that the bottom side of the specimen was still dry. It was assumed that more time is needed to have water at the bottom side of the sample. Otherwise, a new modification should be made to the standpipe to have high water pressure. It was then concluded that the stabilized soil would undoubtedly have a relatively low coefficient of permeability. Regarding the subgrade material, this condition means that it is unlikely that water will pass from the ground through to the upper layer of the road pavement and vice versa. This condition is expected to prevent water from leaching cement paste, binders, and fine materials. 
The stress-strain curves of specimens tested on the $7^{\text {th }}$ day of curing time are presented in Fig. 3. It can be seen that the non-stabilized soil has a strain value of about $3 \%$ at a corresponding maximum stress of about $0.25 \mathrm{MPa}$. On the other hand, all stabilized soils have a strain value of about $1.5 \%$ at similar maximum stress between $1 \mathrm{MPa}$ and $1.2 \mathrm{MPa}$, indicating a significant influence of the stabilization on the material stiffness and overall rigidity. From Fig. 3, the ultimate UCS value of the non-stabilized soil was only $0.2 \mathrm{MPa}$ compared to $1.0 \mathrm{MPa}$ of the sample treated with $15 \%$ slag (i.e., Mix-1). On the other hand, replacing $1.5 \%$ of the slag with cement (Mix-2) increased the UCS value from $1.0 \mathrm{MPa}$ to almost 1.2 MPa. The highest UCS value of $1.2 \mathrm{MPa}$ is still below the minimum UCS value of $1.724 \mathrm{MPa}$ (i.e. UCSmin $=1.724 \mathrm{MPa}$ ) required by Austroads for road subgrade.

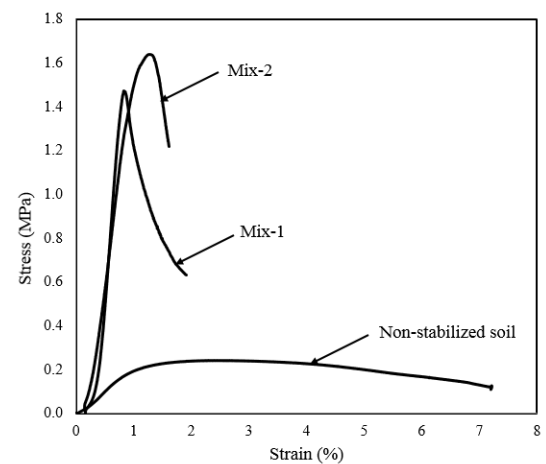

Fig. 4. Stress-strain curves of UCS tests of nonstabilized and stabilized soils $\left(14^{\text {th }}\right.$ day).

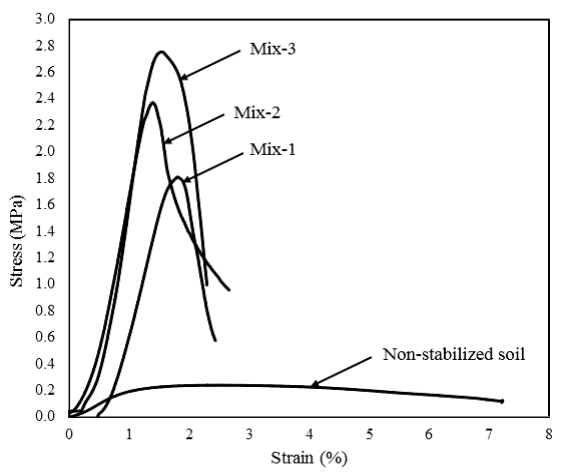

Fig. 5. Stress-strain curves of UCS tests of nonstabilized and stabilized soils ( $28^{\text {th }}$ day).

The same trends were observed for samples cured for 14 and 28 days, as shown in Fig. 4 and 5. The UCS results after 14 days curing time shown in Fig. 4 were found to be higher than those for the seven-day curing time, reflecting the increase of strength with time. This indicates that the pozzolanic reaction still occurs on stabilized soil after seven days curing time, whereas the small increase of then non-stabilized soil is the effect of the reduction of water content on the specimen. The mixture coded as Max-2 (i.e. the mix that contains soil stabilized with $13.5 \%$ slag $+1.5 \%$ cement) satisfied the minimum UCS value required by Austroads for road subgrade. Fig. 6 shows a summary of the UCS enhancement scale at different curing times. The stabilized soil with the proportion of $13.5 \%$ slag $+1.5 \%$ cement passed the minimum UCS value required for subgrade. This proportion is more efficient than the one with $12.75 \%$ slag $+2.25 \%$ cement from economic point of view.

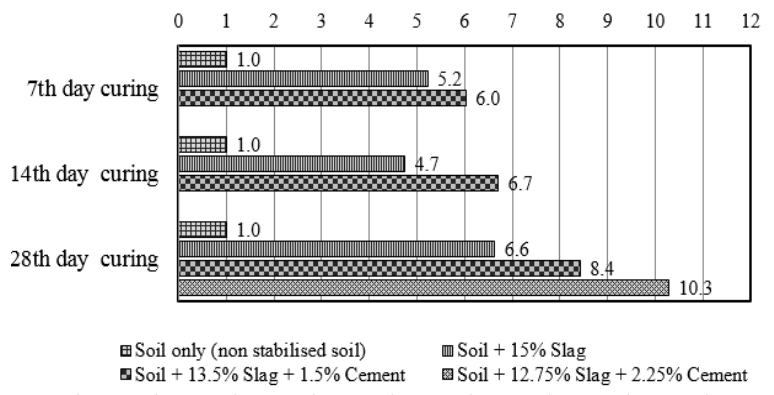

Fig. 6. The strength enhancement scale of the UCS value for different mixtures and curing time.

The selected mixture of stabilized soil with $13.5 \%$ slag $+1.5 \%$ cement was used for the CBR tests. Three penetration levels of three samples during load increments in the CBR tests were used to calculate an average value after four days soaking; the corresponding 
CBR value was found to be equal to $61.70 \%$. This means that the CBR value of the stabilized soil is four times higher than the minimum CBR value required for subgrade, as recommended by Austroads for pavement design $(\mathrm{CBR} \min =15 \%)$.
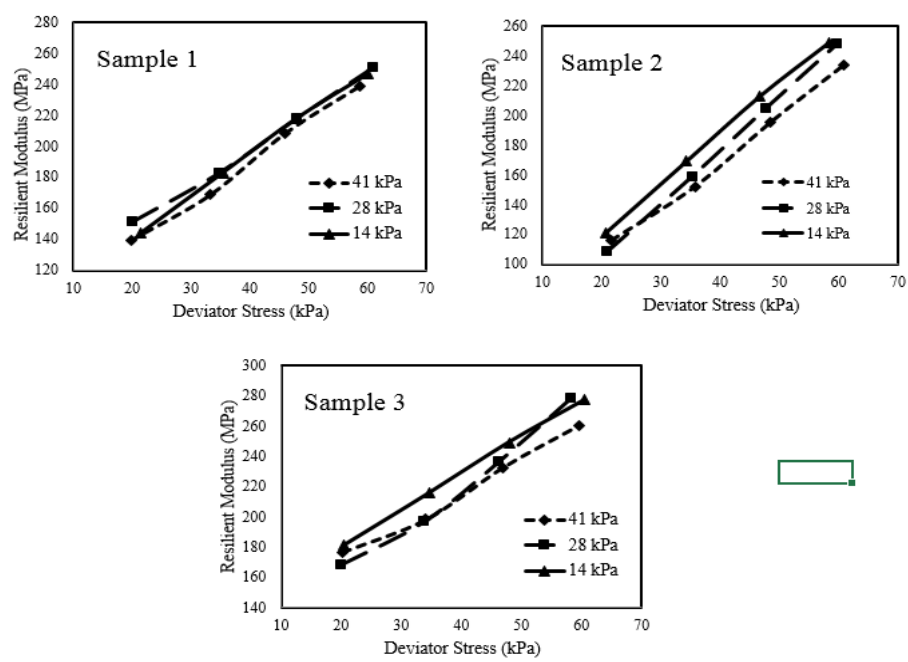

Fig.7. Correlation between resilient modulus and deviator stress under different confining pressures.

In designing a highway pavement, engineers commonly rely on the results of the CBR test of the subgrade to assess both performance of the native soil and adequacy of the stabilized material. However, Satyanarayana and Rama [14] pointed out that the CBR testing method is limited due to its practical nature. Cheung [15] suggested that the resilient modulus should be used to assess the stiffness of subgrade material. This test is necessarily a cyclic version of the conventional monotonic triaxial compression test, the cyclic or repeated load application is thought to more accurately simulate actual traffic loading, which is usually imposed on road pavement layers.

As mentioned earlier, in the repeated load triaxial tests (RLT), a total of 15 sequences contains three stages of confining pressures were applied to several identical selected mixture specimens included $13.5 \%$ slag $+1.5 \%$ cement. Fig. 7 shows correlation charts for the relationship between the deviator stress $(\sigma d)$ and resilient modulus (MR) of three tested specimens. Regarding the effect of stress state, all curves show the same trend, where the MR value increases with increasing $\sigma \mathrm{d}$. Another trend is that the reduction of confining pressure from 41,28 , and $14 \mathrm{kPa}$ along the repeated loading did not show a significant effect on the resilient modulus value.

Table 5. Generated resilient modulus correlation models.

\begin{tabular}{|c|c|c|}
\hline Model name & Model formulation & $\boldsymbol{R}^{\mathbf{2}}$ \\
\hline Bilinear & $M_{R}=2.77 \sigma_{d}+87.268$ & 0.801 \\
\hline Power & $M_{R}=28.502\left(\sigma_{d}\right)^{0.529}$ & 0.754 \\
\hline Hyperbolic & $M_{R}=\frac{310.6 \sigma_{d}-3904.7}{\sigma_{d}}$ & 0.962 \\
\hline
\end{tabular}

As the change of confining pressure has negligible effects on the resilient modulus, several resilient modulus correlation models were suggested based on the deviator stress 
$(\sigma d)$. The best correlation model was selected based on the highest coefficient determination value (R2) of each model. The generated model formulations and their performance regarding $\mathrm{R} 2$ are summarized in Table 5. It can be seen that the hyperbolic model produced the highest resilient modulus.

\section{Conclusions}

The use of slag (with cement) to stabilize an expansive subgrade soil from Baldivis (Perth, Western Australia) was performed through a series of comprehensive geotechnical investigation supported by extensive laboratory tests. Three stabilizer proportions have been designed and applied to stabilize the expansive soil on various mixtures. Based on the laboratory test results, the following conclusions are reached. Soil stabilized in the current study can be classified as medium expansive concerning the activity index of 1.5 and free swell index of $91 \%$. This stabilized soil may also be classified as a low permeable subgrade, which would prevent groundwater through to the adjacent pavement layers. Soil stabilized for subgrades may combine chemical and mechanical processes, the recommended additive proportion to maintain the expansive soil used in the current study is found to be $13.5 \%$ slag $+1.5 \%$ cement. This mixture was proven to be effective in satisfying the required specifications for subgrade of road pavements based on the UCS test results at 28 days of curing and CBR value of about four times higher than the reference value of the non-stabilized soil. The enhancement of the $\mathrm{pH}$ value of the stabilized soil compared with non-stabilized soil is a result of the pozzolanic reaction between the soil and stabilizers. Furthermore, the basicity behavior of the stabilized soil could contribute to the strength development of Portland cement hydration. The hyperbolic correlation model was the best to represent the resilient modulus of the stabilized soil.

\section{References}

1. D.G. Fredlund, J. of Geotech. and Geoenv. Eng. 132, 3 (2006)

2. A. Karunarsthne, Proc. the 22nd ACMSM (2012)

3. D. Neeraja, A.V.N. Rao, Int. J. of Eng. Sci. and Tech. 2, 11 (2010)

4. O. Gregory, D. Jones, Proc., Australasian Slag Association Conference (2011)

5. G. Veith, Build. Res. and Information, 28, 1 (2000)

6. L. Yadu, R. Tripathi. Procedia Engineering 51 (2013)

7. M.R. Ouf, Stabilization of clay subgrade using ground granulated blastfurnace slag (PhD Thesis, University of Leeds, Leeds, 2001)

8. D.D. Higgins. Soil stabilization with ground granulated blastfurnace slag-UK Res. and practical experience report (UK Cementitious Slag Assoc. CSMA, 2005)

9. A. Kavak, G. Bilgen, O.F. Capar, J. of ASTM Int. 8, 7 (2011)

10. E. Cokca, V. Yazici, V. Ozaydin, Geotech. and Geol. Eng. 27, 4 (2008)

11. J. Lu, C. Modmoltin, K. Onitsuka, 2004. J. Env. Sci. 16, 3 (2004)

12. AS 1289, Standard Methods of Testing Soils for Engineering Purposes (SAI, 2000)

13. AASHTO T307-99, Standard Methods of Tests (AASHTO, 1999)

14. R. Satyanarayana, M. Rama, (2005). Int. J. of Pavement Eng. 6, 3 (2005)

15. L.W. Cheung, Laboratory assessment of pavement foundation materials $(\mathrm{PhD}$ Thesis, University of Nottingham, Nottingham, 2000) 